\section{O URBANISTA E O RIO DE JANEIRO: JOSÉ DE OLIVEIRA REIS, UMA BIOGRAFIA PROFISSIONAL}

Rodrigo de Faria

São Paulo: Alameda Casa Editorial; FAPESP, 2013.

Lúcia Helena Pereira da Silva

Universidade Federal Rural do Rio de Janeiro, Instituto Multidisciplinar, Nova Iguaçu, RJ, Brasil

O estudo do urbanismo e/ou do pensamento urbanístico na cidade do Rio de Janeiro é recorrente na historiografia brasileira. No entanto, a utilização de biografia, especificamente de uma biografia profissional, parece-me um encaminhamento bastante original ao tema.

Rodrigo Faria, apoiado em farta documentação, retoma o contexto de institucionalização do urbanismo em terras cariocas, enfrentando o desafio de, por meio de uma trajetória biográfica profissional, descortinar os momentos de tal processo. Uma questáo perpassa a biografia e as instituiçôes sobre as quais a pesquisa se debruça: como o biografado lia/entendia o urbanismo - não sei se no Brasil, como o autor gostaria, mas, com certeza, no Rio de Janeiro, como bem indica o titulo do livro. Para dar conta de sua proposta, o pesquisador constrói uma narrativa em quatro capítulos, seguidos de um instigante posfácio.

Sob a inscriçãa de historiógrafo, o autor começa a descortinar a vida profissional do engenheiro José de Oliveira Reis, doutor Reis, para aqueles que o conheceram, estando eu mesma incluída nesse grupo. Ao lançar mão da "condição de historiógrafo" para interpretar o diálogo do engenheiro com o seu passado - esse é o exercício feito pelo autor com base nos escritos do Dr. Reis -, o início da carreira do engenheiro é analisado a partir de uma interpretaçáo consolidada que o próprio biografado faz de sua trajetória.

Conceitos como "verdade histórica" e "circularidade de ideia" ganham novos sentidos. O primeiro é visto, da ótica do biografado, como memória da cidade, que o pesquisador náo reconhece como memorialista mas como historiógrafo; o segundo é percebido a partir da leitura e análise dos documentos produzidos nos anos 1960 e 1970 pelo engenheiro, potencializando a construção de uma interlocução com os sujeitos e eventos do início de sua carreira. Dessa forma, o primeiro capítulo apresenta a análise do pesquisador acerca da interpretação do processo de introdução das questôes urbanísticas na administração pública municipal, a partir da figura do Dr. Reis, mas não só dele, já que ele é representativo de um grupo de engenheiros. $\mathrm{O}$ curioso é que o biografado o faz sem atentar que ele mesmo náo participara de parte do processo, posto que só entrara para a prefeitura em 1932 e o mesmo remonta à década de 1920.

$\mathrm{O}$ engenheiro explicitou uma interpretação que se tornou hegemônica dentro de um determinado grupo, ainda que pouco conhecida fora dele. Por décadas, a administração pública municipal atuou na estrutura urbana com base nessa leitura. A interpretação de Reis é hegemônica (não sem tensáo) no sentido de ter garantido, ao grupo e à máquina burocrática construída por ele, o controle das intervençóes no espaço urbano, daí ser considerada a memória viva da cidade. No entanto, ao mesmo tempo, ela representa uma leitura opaca, pois era compartilhada por um grupo restrito e de difícil resgate. Parte dessa história só pode ser contada, nesse sentido, pelo próprio historiógrafo.

O segundo capítulo traz à cena a formalização do urbanismo (de novo, não sei se na administração brasileira, mas, seguramente, na carioca) em um processo ricamente detalhado, em particular no que se refere ao significado que o grupo de José de Oliveira Reis deu à transformação da cidade por meio de suas intervençôes.

Com a preocupação de analisar a ação (intervenção) como um pensamento operado por planos e projetos, são articulados, no livro, o lugar profissional e as condiçôes de constituição de um discurso competente naquilo que melhor representou essa simbiose: a Comissão do Plano da Cidade. Pela história dessa comissão, o autor resgata e concatena planos (como os da Esplanada do Morro de Santo Antônio e o do Bairro Peixoto), sujeitos (Reidy, Godoy, E. Passos, etc.) e lugares sociais (Sociedade de Engenheiros e a própria Comissão). 
Como demonstra Faria, a Comissão do Plano da Cidade configurava-se como espaço profissional, institucional e político, por excelência. Assim, ainda que suas açôes pudessem ser lidas a partir da esfera estritamente municipal e técnica, é visível que elas demandaram a integraçáo de todos os âmbitos do poder público, sobretudo o federal. Isso aponta para a constituição de um imaginário profissional, para a construção de consensos e para as disputas do campo político em que o engenheiro transitava.

Se as muitas nomenclaturas (plano de melhoramentos ou plano diretor) davam conta da diversidade de leituras, a preocupação com os aspectos voltados à circulação permitia que os diferentes olhares fossem incorporados em um princípio norteador da atuação da Comissão. Somente sob esse prisma é possível entender a abertura da Avenida Presidente Vargas no período da ditadura do Estado Novo e a sua articulaçáo aos eixos viários, aos túneis propostos em outros projetos, ao problema das inundaçôes e à própria reorganização da administraçâo pública municipal.

A atuação do engenheiro sobre a cidade tanto nos ajuda a construir o seu lugar profissional, produto de sua trajetória, quanto nos permite constituir os espaços institucionais na administração municipal. Ao percorrer a passagem da Comissão do Plano para o Departamento de Urbanismo, no terceiro capítulo, Faria desvela esse processo coletivo, heterogêneo e complexo, especialmente porque escolhe ressaltar uma interpretação que contempla um movimento mais amplo, cuja inteligibilidade extrapola a própria cidade e que pode ser pensada em nível nacional. Para dar conta dessa escolha, ele resgata eventos nacionais como I Congresso Brasileiro de Urbanismo, o surgimento dos "departamentos de urbanismo" no Rio de Janeiro e em São Paulo e a constituição de um imaginário profissional que pôs o plano no ápice das atividades dos especialistas - este último mobilizando leituras de campos disciplinares diferentes.

Tais leituras transformaram, na década de 1950, o departamento de urbanismo do Rio de Janeiro em um espaço de disputa de prática profissional, a qual pode ser exemplificada na alternância das chefias de Reis e Reidy, entendidas como representaçôes de um modo de atuar na cidade, isto é, as maneiras de operar da engenharia e da arquitetura, respectivamente. As práticas de urbanismo dos dois não são interpretadas como divergências pessoais, mas como visões institucionalizadas de dois campos de conhecimento inseridos em uma vasta rede de relaçôes políticas, que iam desde o movimento municipalista à arquitetura moderna, além, é claro, da própria dinâmica da administração pública.

A partir do processo de "aprimoramento" (noção incorporada pelo autor) da estrutura burocrática municipal, chega-se ao quarto capítulo epílogo da carreira do funcionário público municipal. Os espaços institucionais são analisados com vistas a construir uma completude para a trajetória profissional do engenheiro. A Superintendência do Urbanismo e Saneamento (SURSAN) é apresentada como um espaço em que certa forma de pensar é consolidada, mais especificamente aquela relacionada à valorizaçáo da capacidade de financiamento do órgão executor como indutor da realização/efetivação dos planos. Aliás, é interessante assinalar que os projetos confeccionados na Comissão do Plano eram aqueles que estavam sob a alçada de execução da autarquia SURSAN. Considerando isso, o aprimoramento é pensado como uma especialização de funçôes, articulada à leitura dos lugares profissionais dos agentes alocados na máquina administrativa.

Os projetos do Aterro do flamengo e da Avenida Perimetral ${ }^{1}$ são pontos de inflexão nos quais, mais uma vez, é possível discutir a junção entre a formação de um pensamento urbanístico e a intervenção a partir do lugar social ocupado, por exemplo, pelo Departamento de Urbanismo, pela SURSAN e pela Divisão de Engenharia de Tráfego (esta última sendo a ratificação de um processo que elegeu a circulaçáo como elemento catalisador de um pensar sobre a cidade). $\mathrm{O}$ ciclo de atuação do engenheiro urbanista fecha-se com a emergência de seu papel como historiógrafo do urbanismo em terras cariocas.

O posfácio me instigou, não tanto pelo seu conteúdo, ainda que reconheça o trabalho concei-

1 Via elevada expressa na região central da cidade que ligava a Zona Sul, através do corredor viário do Aterro do Flamengo, à Avenida Brasil. Esta última, principal via expressa do município, interligando Zona Norte, Subúrbio e Zona Oeste. A Perimetral foi derrubada em 2014. 
tual da defesa da biografia em detrimento da trajetória profissional, mas pelo que foi capaz de me fazer evocar. Lembrei-me, por exemplo, das entrevistas que fiz, entre 1992 e 1993, com os engenheiros Dr. Reis e Dr. Abelardo Coimbra Bueno e com o arquiteto Durval Lobo, que não gostava de ser chamado de doutor. O doutor Reis morava em um apartamento na rua Barata Ribeiro (ou Toneleiro, já não me lembro bem), quase esquina com Santa Clara, em Copacabana. Ele me recebeu em seu escritório, um cômodo escuro, porque, como estava quase cego, a claridade lhe era indiferente. Movimentava-se com desenvoltura em casa e continuava lendo tudo que lhe chegava à máo com um aparelho que, semelhante a uma máquina de microfilme, aumentava enormemente as letras. $\mathrm{O}$ velhinho magro, mas bastante agitado no alto dos seus 90 anos, estava separando a documentação que iria doar ao arquivo da cidade. $\mathrm{O}$ escritório era um amontoado de caixas, produto da resolução do dilema sobre o que publicizar. O resultado final dessa separação só soube mais tarde, quando fui ao arquivo e pude ver o que fora doado.

Das entrevistas, só me lembro de ele ter-me contado como saía correndo da Politécnica, no largo do São Francisco, para a Belas Artes, na Rio Branco, para algumas aulas, ou da personalidade de Armando de Godoy que, até então, eu desconhecia. Não pude aproveitar aqueles encontros com café e biscoito, dado o fato de o telefone interromper-nos o tempo todo; ele dizia que era o pessoal da secretaria desejando alguma informação, pois "sabia tudo da Cidade".

Nesses momentos, pude conhecer um pouco da "pessoa" do Dr. Reis, que me falou de seu encanto pela cidade do Rio de Janeiro, quando nela chegou, nos anos 1920, para estudar, e de como voltou para sua cidade natal, onde não conseguiu ficar, retornando definitivamente para a cidade que escolheu como sua. Presenciei também seu respeito e admiração pelo "chefe" Armando de Godoy (por conta disso, fez o grupo de pesquisa fazer loucuras para chegar ao neto dele), o carinho por sua companheira de toda vida e sua visão intransigente do urbanismo, relacionada à capacidade de resolver os problemas urbanos, algo próprio de uma geração de engenheiros urbanistas.
O posfácio resgatou todas essas lembranças, e talvez seja por isso que concorde com a proposição de uma biografia profissional e não de uma trajetória, como mormente preferiria, já que Dr. Reis dedicou-se não só profissionalmente mas integralmente à cidade que escolheu viver. A vida carrega o imponderável e, no caso do engenheiro biografado, podemos vê-lo nos fragmentos/rastros por ele deixados (e intencionalmente escolhidos) nos labirintos da cidade.

Em tempos em que o discurso da derrubada da Avenida Perimetral possui a mesma força (estética) de argumentação daquela utilizada para a abertura da Avenida Presidente Vargas, percorrer a trajetória de um profissional que ajudou a construir, com sua atuaçáo, esse discurso permite-nos entender o poder de enunciação do urbanismo e seus limites: a própria cidade.

Lúcia Helena Pereira da Silva: Irentesilva@ig.com.br.

\section{A COPA DO MUNDO E AS CIDADES: POLÍTICAS, PROJETOS E RESISTÊNCIAS}

Fernanda Sánchez,

Glauco Bienenstein, Fabrício Leal de Oliveira

e Pedro Novais (Org.)

Niterói: Editora da UFF, 2014.

Eduardo Alberto Cusce Nobre

Universidade de São Paulo, Faculdade de Arquitetura e Urbanismo, São Paulo, SP, Brasil

Com as confirmaçôes do Brasil e do Rio de Janeiro como sedes, respectivamente, da Copa do Mundo FIFA 2014 e dos Jogos Olímpicos de 2016, uma serie de atuaçóes do poder público e da iniciativa privada em diversas esferas foi intensificada, a fim de garantir a realização desses dois megaeventos esportivos. Os interesses bilionários que os patrocinam fizeram com que determinadas intervençôes 